\title{
Visinin-like protein 1 regulates natriuretic peptide receptor $B$ in the heart
}

Jens Buttgereit ${ }^{1,2}$, Fatimunnisa Qadri ${ }^{1,2}$, Jan Monti ${ }^{1,2}$, Thomas H. Langenickel ${ }^{3}$, Rainer Dietz $^{2}$, Karl-Heinz Braunewell ${ }^{4}$, Michael Bader ${ }^{1}$

${ }^{1}$ Max-Delbrück-Center for Molecular Medicine (MDC), Campus Berlin-Buch, Berlin, Germany;

${ }^{2}$ Medical Faculty of the Charité, Experimental and Clinical Research Center (ECRC), Franz Volhard Clinic, Berlin, Germany

${ }^{3}$ Bristol-Myers Squibb Company, Discovery Medicine and Clinical Pharmacology, Princeton, NJ, USA

${ }^{4}$ Molecular \& Cellular Neuroscience Laboratory, Southern Research Institute, Birmingham, AL, USA

Key Words: Visinin-like protein-1, VILIP-1, Natriuretic Peptide Receptor B, NPR-B, cardiac hypertrophy, heart failure

Authors for correspondence:

Michael Bader, $\mathrm{PhD}$

Max-Delbrück-Center for Molecular

Medicine (MDC) Berlin-Buch

Robert-Rössle-Str. 10

13092 Berlin, Germany

Phone: +49-30-9406-2193

Fax: +49-30-9406-2110

e-mail: mbader@mdc-berlin.de
Jens Buttgereit, $\mathrm{PhD}$

Max-Delbrück-Center for Molecular

Medicine (MDC) Berlin-Buch

Robert-Rössle-Str. 10

13092 Berlin, Germany

Phone: +49-30-9417-1815

Fax: +49-30-9417-1816

e-mail: jens.buttgereit@charite.de 


\begin{abstract}
Accumulating evidence indicates that Visinin-like protein-1 (VILIP-1), a member of the family of neuronal calcium sensor proteins (NCS), modulates a variety of processes in extra-neuronal tissues. In this study, we describe VILIP-1 expression in the human heart, rat cardiomyocytes, and H9c2 cells, and demonstrate that VILIP-1 regulates the cell surface localization of natriuretic peptide receptor B (NPR-B). In preparations from failing hearts, we observed VILIP-1 downregulation and reduced NPRB signalling. In conclusion, VILIP-1 deficiency may be responsible for the reduced efficiency of the natriuretic peptide system in cardiac hypertrophy and heart failure and may therefore serve as pharmacological target.
\end{abstract}




\section{Introduction}

Neuronal calcium sensor proteins (NCS) comprise a family of more than 40 calcium-binding proteins belonging to the super-family of EF-hand proteins. This family includes members of recoverins, guanylyl cyclase-activating proteins (GCAPs), frequenins, $\mathrm{K}^{+}$-channel interacting proteins (KChIPs) and visinin-like proteins (VILIPs). VILIPs, including VILIP-1 to -3, hippocalcin, and neurocalcin$\delta$ are differentially expressed throughout the nervous system [1]. $\mathrm{Ca}^{2+}$ binding to the EF-hand motifs of NCS leads to conformational changes which facilitate binding to lipid bilayers via $\mathrm{Ca}^{2+}$-myristoyl switching [2].

VILIPs have been shown to be implicated in a broad spectrum of physiological and pathophysiological processes including synaptic plasticity, hypertension, neuropathological diseases, cancer, and insulin secretion [3-8]. These effects are possibly mediated by actions on membrane receptors and ion channels such as the natriuretic peptide receptor B (NPR-B) and the nicotinic acetylcholine receptor [9, 10]. VILIP-1 modulates clathrin-dependent receptor cycling in the central nervous system supporting its general role in membrane trafficking [9]. VILIP-1 has also been shown to regulate gene expression by formation of protein-RNA-complexes that modulate localization and stability of specific mRNAs and possibly by affecting the cAMP/CREB pathway $[8,11]$.

VILIP-1 is expressed at high levels in the brain and its role in the central nervous system has been addressed in a number of studies [6, 11-13]. Expression of VILIP-1 was also reported for the heart, pancreas, reproductive organs, and colon, however, its function in extra-neuronal tissues is still poorly understood [14].

The natriuretic peptides comprise a family of the structurally related but genetically distinct peptide hormones, atrial (ANP), brain (BNP) and C-type natriuretic peptide (CNP). They exert their biological actions by binding to cell surface receptors divided into particular guanylyl cyclase-coupled receptors NPR-A and $-\mathrm{B}$ and the clearance receptor NPR-C [15, 16]. NPR-B has recently been shown to mediate antihypertrophic actions of its ligand C-type natriuretic peptide in vitro and in vivo thereby serving as potential pharmacological target for the treatment of cardiac hypertrophy and heart failure [17]. Only a few factors that are 
involved in the regulation of NPR-B have been identified so far: The transcriptional factor Sp1, protein kinase C (PKC), $\mathrm{Ca}^{2+}$ as well as VILIP-1 in neuronal cells [9, 18-20]. This study was designed to analyze cardiac expression of VILIP-1 and its role in modulating NPR-B signalling in vitro and in failing hearts. 


\section{Methods}

\section{Reagents and Materials}

C-type natriuretic peptide (CNP-22) and Arg-vasopressin were obtained from Calbiochem (Darmstadt, Germany). 3-isobutyl-1-methylxanthine (IBMX) was obtained from Sigma (Munich, Germany). Cell culture reagents were from Biochrom (Berlin, Germany). ${ }^{125} \mathrm{I}$-CNP-22 was supplied by Phoenixpeptide (Karlsruhe, Germany), ${ }^{125}$ I-cGMP and L-[3, 4]- ${ }^{3} \mathrm{H}-$ Leucine by GE Healthcare (Munich, Germany). Immunocytochemistry

Cardiomyocytes were preparated as described [21, 22]. Methanol-fixed cells were washed with phosphate-buffered saline containing $0.1 \%$ Triton-X-100. Samples were blocked by using $2 \%$ normal donkey serum. Cells were incubated overnight at $4^{\circ} \mathrm{C}$ with a VILIP-1 antibody (1:1.000) [14]. On the next day, cells were incubated with an anti-rabbit Cy3-conjugated secondary antibody (1:500, Jackson ImmunoResearch, West Grove PA) and mounted using Vectashield medium (Vector laboratories, Burlingame, CA). Fluorescent images were collected using a Leica DMI6000MB microscope.

\section{Protein preparation, SDS-PAGE and Western blot}

Samples were homogenized in RIPA buffer containing the "complete mini Protease inhibitor cocktail” (Roche, Mannheim, Germany). Proteins were isolated by centrifugation (5.000 x g, $10 \mathrm{~min}, 4^{\circ} \mathrm{C}$ ), quantified by BCA method (Pierce, Rockford, USA), separated on a 12\% Tris-Glycine gel (Serva, Heidelberg, Germany) and blotted onto a nitrocellulose membrane (Whatman, Dassel, Germany). VILIP-1 was detected with the antibody described above and a horseradish peroxidase-conjugated anti-rabbit antibody (Sigma, Munich, Germany) using the ECL-Plus Western Detection System (GE Healthcare, Munich, Germany). The same membrane was stripped, GAPDH protein was detected with an mouse monoclonal antibody (GAPDH 6C5, Santa Cruz).

Transfection of expression vectors and siRNA

H9c2 cells (ATCC, USA) were cultured in $25 \mathrm{~cm}^{2}$ flasks in Dulbeccos modified Eagles medium (DMEM) supplemented with $10 \%$ calf serum. Transfection was carried out with Lipofectamine 2000 (Invitrogen, Karlsruhe, Germany). 24 hours after transfection cells were subcultured and $48 \mathrm{~h}$ post transfection DMEM supplemented with serum and G418 (300 $\mu \mathrm{g} / \mathrm{ml})$. 
For siRNA studies cells were cultured in 6 well plates. 200 pmol of siRNA per well (Rn_Vsnl1_1_HP siRNA SI00251790; Rn_Vsnl1_5_HP SI03021333; AllStars negative control; Qiagen, Germany) were

transfected using Lipofectamine $e^{2000}$. The medium was changed after 24 hours and cells were used for experiments 48 hours after transfection.

\section{Stimulation and determination of intracellular cGMP production}

Cells were washed with PBS and stimulated with DMEM containing $1 \mathrm{mM}$ IBMX, 0.5\% BSA and CNP ranging from $1 \mathrm{nM}$ to $1 \mu \mathrm{M}$ for 20 minutes at $37^{\circ} \mathrm{C}$. The reaction was stopped by placing culture dishes on ice and disrupting the cells by sonication. Determination of cGMP concentration was done by radioimmunoassay as described previously [23].

\section{CNP-binding assay}

H9c2 cells, cultured in 6- well plates were washed twice with PBS and incubated with serum-free DMEM containing $100 \mathrm{nM}{ }^{125}$ I CNP-22 for different periods of time. After washing, cells were lysed with $1 \mathrm{M} \mathrm{NaOH}$ containing $1 \%$ Triton-X-100, then neutralized with $1 \mathrm{M} \mathrm{HCl}$ and the radioactivity of each well was determined (Wallac 1470, PerkinElmer, Waltham, USA).

\section{Leucine incorporation}

H9c2 cells overexpressing pEGFP-VILIP-1 (enhanced green fluorescent protein) or pEGFP were cultured in 12 well plates until 50\% densitiy was reached. For inducing quiescence, DMEM containing $10 \%$ NCS was replaced by serum free medium. After incubation for 24 hours, cells were stimulated with $100 \mathrm{nM}$ vasopressin alone or in combination with $50 \mathrm{nM}$ CNP for $12 \mathrm{~h}$ at $37^{\circ} \mathrm{C}$. L-(4,5)- ${ }^{3} \mathrm{H}-$ Leucine incorporation was performed as described. [17]. The L-(4,5)- ${ }^{3} \mathrm{H}$-Leucine incorporation of non-stimulated cells (basal) was set at 100\%.

\section{Experimental myocardial infarction}

Experiments involving laboratory animals were conducted in accordance with the local authorities and conforming to the National Institutes of Health Guide for the Care and Use of Laboratory Animals (National Institutes of Health publication no. 85-23, revised 1996). Myocardial infarction was induced in Sprague Dawley rats (body weight 200 g) as described previously [24]. Four weeks after induction, cardiac function was assessed.

\section{Echocardiography}


Two-dimensional guided M-mode echocardiography was performed as described [17].

Invasive hemodynamic measurement

Under anesthesisa with isoflurane, a 2-F catheter (Aria, Millar Instruments) was advanced into the right coronary artery and inserted into the left ventricle for measurement of contractility $\left(\mathrm{dP} / \mathrm{dt}_{\max }\right)$, relaxation ( $\left.\mathrm{dP} / \mathrm{dt}_{\min }\right)$ and left ventricular end-diastolic pressure (LVEDP). After hemodynamic measurement, rats were euthanized and the organs were rapidly dissected. The heart was dissected into the chambers and the scar was removed from the non-infarcted area. Samples were immediately frozen in liquid nitrogen and stored at $-80^{\circ} \mathrm{C}$ until further analysis.

RNA-extraction, RNase Protection Assay and Real-time PCR

Total RNA was extracted with Trizol ${ }^{\circledR}$ (Invitrogen; Karlsruhe, Germany) VILIP-1 and GAPDH transcripts were amplified by RT-PCR from pEGFP-VILIP-1 or from rat cDNA pool (Primer sequences: supplementary file). PCR fragments were cloned into pGEM-Teasy vector and antisense probes were labelled with $\left[{ }^{32}\right.$ P]UTP (Promega). VILIP-1 and GAPDH expression was measured by RNase protection assay as described [17].

For cDNA synthesis, $2 \mu \mathrm{g}$ total RNA were reverse transcribed with oligo-dT (Omniscript, Qiagen). Expression of NPR-B was analyzed by real-time PCR (TaqMan Master Mix, Applied Biosystems; Primer sequences: supplementary file).

Preparation of membranes and guanylyl cyclase assay

The non-infarcted area of the left ventricle was homogenized in phosphatase inhibitor buffer containing 25 mM HEPES (pH 7.4), 50 mM NaCl, 20\% glycerol, 50 mM NaF, 2mM EDTA, $0.5 \mu \mathrm{M}$ microcystin and the protease inhibitor cocktail. After centrifugation at $10,000 \mathrm{x} \mathrm{g}$ for $10 \mathrm{~min}$ at $4{ }^{\circ} \mathrm{C}$, the pellet was washed twice with the phosphatase inhibitor buffer. After resuspension, total protein concentration was determined by the Bradford method. Immediately after preparation $80 \mu \mathrm{g}$ protein were used for assaying guanylyl cyclase activity as described [23].

Determination of BNP plasma level

Plasma samples were purified on C18 Sep-Pak colums (Waters), BNP concentrations were determined by a radioimmunoassay (Bachem).

Statistical Analysis 
The differences between groups were evaluated by analysis of variance (ANOVA), or paired Student`s t-test where appropriate. The significance level was set at $\mathrm{p}<0.05$. All data are expressed as mean \pm standard error of the mean (SEM). 


\section{Results}

VILIP-1 is expressed in cardiomyocytes

VILIP-1 mRNA expression was tested in a broad range of tissues derived from Sprague Dawley rats by RNase protection assay. VILIP-1 was expressed in all organs tested including cardiac chambers. The housekeeping gene GAPDH served as control (Fig. 1A). VILIP-1 expression was detected by western blot in lysates from human and rat samples from the left ventricle as well as in H9c2 cells (single band of $\sim 22 \mathrm{kDa}$; Fig. 1B). The expression of VILIP-1 was confirmed by immunocytochemistry in cardiomyocytes and H9c2 cells (Fig. 1C-E).

VILIP-1 regulates NPR-B membrane association in vitro

H9c2 cells are derived from rat embryonic cardiomyocytes and expresses VILIP-1 (Fig. 1B, E) and NPR-B as confirmed by RT-PCR and enzyme activity studies [17, 23]. Cells were transfected with pEGFP-VILIP-1 or the empty vector (mock) and the expression was confirmed by the detection of the EGFP fluorescence (Fig. 2A).

Stimulation with CNP led to a dose-dependent increase of intracellular cGMP production in both groups. However, in VILIP-1 overexpressing H9c2 cells, CNP induced a significantly higher cGMP response (Fig. 2A). To determine the receptor density of NPR-B on the cell surface, cells were incubated with ${ }^{125}$ I-CNP-22. These studies revealed an increased number of binding sites in VILIP-1 overexpressing H9c2 cells, confirming an increased number of NPR-B molecules at the cell surface (Fig. 2B). In contrast, siRNA-induced reduction of VILIP-1 expression in H9c2 cells led to a decreased CNP-dependent cGMP response with a reduced binding of ${ }^{125}$ I-CNP (Fig. 2C, D).

VILIP-1 influences antihypertrophic potential of CNP in H9c2 cells

Arg-vasopressin induced a similar increase of protein synthesis in H9c2 cells stably transfected with VILIP-1 or mock. The hypertrophy was partially blocked by CNP in both groups. However, the potency of CNP to block the Arg-vasopressin effect was higher in VILIP-1-overexpressing cells (Fig. 3A). In H9c2 cells with reduced VILIP-1 and controls, vasopressin exposure led to a similar protein synthesis. This process was prevented by CNP in H9c2 cells treated with unrelated siRNA, but not in those with reduced VILIP-1 expression (Fig. 3B).

Induction of myocardial infarction in rats 
Ligation of the LAD (left anterior descending artery) was performed to induce myocardial infarction (MI) of the left ventricle in rats. Echocardiography, invasive hemodynamic measurement and determination of plasma BNP was performed to determine cardiac dimensions, systolic and diastolic dysfunction (Table 1).

Cardiac hyporesponsiveness to CNP in experimental myocardial infarction

To determine cardiac responsiveness of NPR-B to hormonal stimulation, we prepared heart membranes from the non-infarcted area of the left ventricle or from a similar region of sham-operated animals and measured cGMP production upon stimulation with a saturating concentration of CNP (Fig. 4). Basal guanylyl cyclase activity was comparable between both groups. The stimulation of membranes with Triton-X100/ $\mathrm{Mn}^{2+}$ are thought to reflect the changes of NPR activity resulting from changes in receptor protein or phorphorylation state of the regulatory domain. Guanylyl cyclase activity in the presence of Triton-X100/ $\mathrm{Mn}^{2+}$ was not significantly altered in cardiac membranes obtained from animals with MI. In contrast, the CNP-dependent cGMP-response in the hearts of rats with MI was significantly reduced to $66 \%(\mathrm{p}<0.05)$ of the activity observed in hearts from shamoperated animals.

\section{Expression of NPR-B, NPR-C and VILIP-1 in experimental myocardial infarction}

To find an explanation for the reduced CNP-dependent cGMP-response, we first analyzed mRNA expression of NPR-B and VILIP-1 in the cardiac samples used for membrane preparations. Gene expression was normalized to GAPDH expression. The expression level of sham-operated animals was set at $100 \%$. The expression of NPR-B was not altered in the infarct group (Sham: $100 \% \pm 9$ vs. MI $83 \% \pm 6$, $\mathrm{p}=0.14$ ). For the clearance receptor NPR-C, a significant upregulation (Sham: $100 \% \pm 8$ vs. MI $267 \pm$ 32, $\mathrm{p}<0.001$ ) was detected. No significant reduction was found for VILIP-1 (Sham $100 \pm$ 32 vs. MI $58 \% \pm 10, \mathrm{p}=0.2)$.

VILIP-1 expression was analyzed by western blot in whole tissue homogenates from samples of the non-infarcted area of the left ventricle and control tissue, respectively. For normalization, GAPDH expression was determined. The expression of VILIP-1 protein was significantly reduced in the left ventricular tissue of rats with MI (Fig. 5 A/B). 


\section{Discussion}

Growing evidence indicates that VILIP-1, a member of the family of neuronal calcium sensor proteins, modulates a variety of processes in extra-neuronal tissues. In this study we demonstrate that VILIP-1 is present in the heart, cultured cardiomyocytes, and H9c2 cells. Overexpression of VILIP-1 in H9c2 cells increased surface expression of NPR-B and led to increased intracellular cGMP production upon CNP exposure. In contrast, siRNA-mediated knockdown of VILIP-1 led to decreased surface expression of NPR-B, thereby reducing the ligand-dependent formation of cGMP. These data demonstrate that VILIP-1 is a key regulator of NPR-B signalling in cardiomyocytes by modulating the amount of receptor molecules in the membrane. This is in accordance with previous studies demonstrating that VILIP-1 may either directly interact with NPR-B or alter clathrin-dependent membrane trafficking of NPR-B in C6 glioma cells [9, 28].

A number of studies have demonstrated antihypertrophic actions of natriuretic peptides on cardiomyocytes in vitro and in vivo [17, 29, 30]. These effects are mediated by NPR-A and B. The cardioprotective role of NPR-A has been recognized many years ago but the knowledge about NPR-B is still evolving [31]. By overexpressing a dominant-negative mutant of NPR-B (NPR-B $\Delta K C$ ), we have recently demonstrated a antihypertrophic function of NPR-B in cardiomyocytes in vitro and in vivo [17]. This receptor is the predominant subtype of the NPRs in the failing heart and beneficial effects of CNP infusion on cardiac structure and performance in rats with experimental myocardial infarction were demonstrated [32].

Because VILIP-1 overexpression increases the CNP-dependent cGMP response, we postulated an increased antihypertrophic potential of CNP. In H9c2 cells, hypertrophy can be induced by different stimuli such as Arg-vasopression or insulin-like growth factor-1 (IGF-1) and can be blocked by ANP, CNP and the membrane permeable cGMP analogue 8-Bromo-cGMP [17, 29]. In VILIP-1 overexpressing cells, CNP exhibited a significantly higher antihypertrophic potential in comparison to controls. Vice versa, siRNA-based knockdown of VILIP-1 abolished the antihypertrophic property of CNP. These results are in compliance with the altered CNP-dependent cGMP-response and underline the importance of this second messenger in mediating antihypertrophic effects in cardiomyocytes and stable cell lines derived from those [17, 29]. 
The second part of this study was to explore a possible relevance of VILIP-1 in congestive heart failure. Increased cardiac expression of ANP and BNP and release of this peptides into the circulation is a characteristic feature in heart failure. Despite this elevation, the physiologic response to these peptides is diminished [33, 34]. Currently two studies were published describing hyporesponsiveness of cardiac and renal tissues to ANP in congestive heart failure. It could be demonstrated that for kidney membranes a reduced amount of NPR-A molecules and not a reduced phosphorylation state may explain the reduced enzymatic activity [35].

For membrane preparations obtained from the non-infarcted area of rats four weeks after surgery, a reduced CNP-dependent cGMP response was detected. This finding is in accordance with the study from Kim et al., describing reduced NPR-B activity in membranes prepared from endocardial cells of the hypertrophied right ventricle [36]. Interestingly in failing hearts from mice with pressure-overload, guanylyl cyclase activity of NPR-B was not affected [37]. Thus the regulation of NPR's seem to depend on several factors such as the origin of heart disease and tissue or differences among species.

A number of factors may be responsible for the reduced activity of NPR-B in the cardiac membranes obtained from rats with MI. These are increased expression of the clearance receptor NPR-C, activation of phosphatases that desensitize NPR-B, transcriptional regulation of NPR-B, alternative splicing of the primary transcript leading to dominant-negative NPR-B isoforms or increased receptor internalization.

An increased expression of NPR-C was decribed in heart failure patients, rats with pressure overloadinduced cardiac hypertrophy and was also observed in our model [38, 39]. For guanylyl cyclase assays a saturating concentration of CNP was applied, so it is unlikely that a increased clearance is responsible for the reduced CNP-dependent cGMP response.

It is well described that PKC and $\mathrm{Ca}^{2+}$ are able to reduce enzymatic activity of NPR-A and -B by activating at least two different phosphatases. This process is known as heterologous desensitization and is characterized by dephosphorylation of the regulatory domain of NPR-A and -B [40-42]. The study of Bryan et al. has demonstrated that receptor dephosphorylation is not the mechanism that lead to renal hyporesponsiveness to natriuretic peptides in heart failure [35]. There are no studies reported in which the phosphorylation state of NPR-A or -B have been determined in failing hearts. In the 
cardiac cell line H9c2, heterologous desensitization of NPR-A and -B can be induced within a few minutes by employing the PKC-activator PMA (phorbol 12-myristate 13-acetate). This effect is blocked by several PKC-inhibitors (unpublished data of J.B.). In heart failure PKC is activated by humoral factors, such as angiotensin, endothelin or catecholamines, so heterologous desensitization of NPR-B may be responsible for the reduced CNP-dependent cGMP response in our model [43].

Furthermore, a reduced mRNA expression or membrane exposition may also be causative for the reduced guanylyl cyclase activity in our model. The gene expression of NPR-B in the noninfarcted part of the left ventricle was not altered. The same result was found in a model of pacing-induced heart failure in minipigs. In this model NPR-B expression was reduced in the right but not in the left ventricle [37].

Given the possibility that VILIP-1 regulates the amount of NPR-B in cardiac membranes, as observed in H9c2 cells, we tested mRNA expression and protein content in whole tissue homogenates. Whereas no significant reduction of mRNA expression was observed, a reduction of VILIP-1 protein level was detected. This may lead to a reduced exposition of NPR-B on the cell surface, explaining the reduced CNP-dependent cGMP-response. Due to the lack of suitable antibodies against NPR-B, including dominant-negative isoforms of this receptor, protein levels can not be determined so far [44].

In summary, this study provides first evidence for a functional role of VILIP-1 in the heart. VILIP-1 may serve as important factor responsible for the downregulation of NPR's in congestive heart failure. It may therefore constitute a potential pharmacological target for the treatment of cardiac hypertrophy and heart failure. 


\section{Acknowledgements}

The authors acknowledge the excellent technical assistance of J. Mothes, A. Schiche and C.

Look. This work was supported by a grant from the "Deutsche Forschungsgemeinschaft" to M.B.

[BA1374/14-1]. 


\section{Reference List}

1. Braunewell K.H., Gundelfinger E.D. Intracellular neuronal calcium sensor proteins: a family of EF-hand calcium binding proteins in search of a function. Cell Tissue Res. 1999; 295:1-12

2. Ames J.B., Ishima R, Tanaka T, Gordon J.I., Stryer L, Ikura M. Molecular mechanisms of calcium-myristoyl switches. Nature 1997; 389:198-202

3. Tzingounis A.V., Kobayashi M, Takamatsu K, Nicoll R.A.Hippocalcin gates the calcium activation of the slow afterhyperpolarization in hippocampal pyramidal cells. Neuron 2007; 53:487-493

4. Palmer C.L., Lim W, Hasti P.G., Toward M, Korolchuk V.I., Burbidge S.A., Banting G, Collingridge G.L., Isaac J.T., Henley J.M. Hippocalcin functions as a calcium sensor in hippocampal LTD. Neuron 2005; 47:487-494

5. Kamide K, Kokubo Y, Yang J, Tanaka C, Hanada H, Takiuchi S, Inamoto N, Banno M, Kawano Y, Okayama A, Tomoike H, Miyata T. Hypertension susceptibility genes on chromosome 2p24p25 in a general Japanese population. J Hypertens.; 2005;23:955-960

6. Braunewell K.H., Riederer P, Spilker C, Gundelfinger E.D., Bogerts B, Bernstein H.G. Abnormal localization of two neuronal calcium sensor proteins, visinin-like proteins (vilips)-1 and -3 , in neocortical brain areas of Alzheimer disease patients. Dement Geriatr Cong Disord. $2001 ; 12: 110-116$

7. Mahloogi H, Ganzález-Guerrico A.M., Lopez De Cicco R, Bassi D.E., Goodrow T, Braunewell K.H., Klein-Szanto A.J. Overexpression of the calcium sensor visinin-like protein-1 leads to a cAMP-mediated decrease of in vivo and in vitro growth and invasivness of squamous cell carcinoma cells. Cancer Res. 2003; 63:4997-5004

8. Dai F.F., Zhang Y, Kang Y, Wang Q, Gaisano HY, Braunewell K.H., Chan C.B., Wheeler M.B. The neuronal $\mathrm{Ca} 2+$ sensor protein visinin-like protein-1 is expresses in pancreatic islets and regulates insulin secretion. J Biol Chem. 2006; 281:21942-21953

9. Brackmann M, Schuchmann S, Anand R., Braunewell K.H. Neuronal Ca2+ sensor protein VILIP-1 affects cGMP signalling of guanylyl cyclase B by regulating clathrin-dependent receptor recycling in hippocampal neurons. J Cell Sci. 2005; 118:2495-2505

10. Lin L., Jeanclos E.M., Treuil M, Braunewell K.H., Gundelfinger E.D., Anand R. The calcium sensor protein visinin-like protein-1 modulates the surface expressionand agonist sensitivity of the alpha 4beta 2 nicotinic acetylcholine receptor. J Biol Chem. 2002; 277:41872-41878

11. Mathisen P.M., Johnson J.M., Kawczak J.A., Tuohy V.K. Visinin-like protein (VILIP) is a neuron-specific calcium-dependent double-stranded RNA binding protein. J Biol Chem. 1999; 274:31571-31576

12. Bernstein H.G., Becker A., Keilhoff G., Gorcyca W.A., Braunewell K.H., Grecksch G. Hippocampal expression of the calcium sensor protein VILIP-1 in schizophrenia. Neurosci Lett. 2003; 339:95-98

13. Braunewell K.H., Brackmann M, Manahan-Vaughan D. Group I mGlu receptors regulate the expression of the neuronal calcium sensor protein VILIP-1 in vitro and in vivo: Implications for mGlu receptor-dependent hippocampal plasticity? Neuropharmacology 2003; 44:707-715

14. Gierke P, Zhao C, Kuhl D, Manahan-Vaughan D, Braunewell K.H. Expression analysis of members of the neuronal calcium sensor protein family: combining bioinformatics and Western blot analysis. Biochem Biophys Res Commun. 2004; 322:1073-1079 
15. Silberbach M, Roberts CT, Jr. Natriuretic peptide signalling: molecular and cellular pathways to growth regulation. Cell Signal. 2001; 13:221-231

16. Potter LR, Abbey-Hosch S, Dickey DM. Natriuretic peptides, their receptors, and cyclic guanosine monophosphate-dependent signaling functions. Endocr Rev. 2006; 27:47-72

17. Langenickel TH, Buttgereit J, Pagel-Langenickel I, Lindner M, Monti J, Beuerlein K, Al-Saadi N, Plehm R, Popova E, Tank J, Dietz R, Willenbrock R, Bader M. Cardiac hypertrophy in transgenic rats expressing a dominant-negative mutant of the natriuretic peptide receptor $\mathrm{B}$. Proc Natl Acad Sci. USA 2006; 103:4735-4740

18. Rahmutula D, Cui J, Chen S, Gardner D. Transcriptional regulation of type B human natriuretic peptide receptor gene promoter: dependence on Sp1. Hypertension 2004; 44:283-288

19. Abbey SE, Potter LR. Vasopressin-dependent inhibition of the C-type natriuretic peptide receptor, NPR-B/GC-B, requires elevated intracellular calcium concentrations. J Biol Chem. 2002; 277:42423-42430

20. Abbey SE, Smirnov D, Potter LR. Differential regulation of NPR-B/GC-B by protein kinase c and calcium. Biochem Pharmacol. 2005; 70:686-694

21. Lamounier-Zepter V., Ehrhart-Bornstein M, Karczewski P, Haase H, Bornstein S.R., Morano I. Human adipocyte attenuate cardiomyocyte contraction: characterization of an adipocyte-derived negative inotropic activity. FASEB J. 2006; 20:1653-1659

22. Dechend R., Homuth V., Wallukat G, Müller D.N., Krause M., Dudenhausen J., Haller H., Luft F.C. Agonistic antibodies directed at the angiotensin II, AT1 receptor in preeclampsia. J Soc Gynecol Investig. 2006; 13:79-86

23. Langenickel T, Buttgereit J, Pagel I, Dietz R, Willenbrock R, Bader M. Forced homodimerization by site-directed mutagenesis alters guanylyl cyclase activity of natriuretic peptide receptor B. Hypertension 2004; 43:460-465

24. Philipp S, Jürgensen JS, Fielitz J, Bernhardt WM, Weidemann A, Schiche A, Pilz B, Dietz R, Regitz-Zagrosek V, Eckardt KU, Eckardt KU, Willenbrock R. Stabilization of hypoxia inducible factor rather than modulation of collagen metabolism improves cardiac function after acute myocardial infarction in rats. Eur J Heart Failure 2006; 8:347-354

25. Kishimoto I, Rossi K, Garbers DL. A genetic model provides evidence that the receptor for atrial natriuretic peptide (guanylyl cyclase-A) inhibits cardiac ventricular myocyte hypertrophy. Proc Natl Acad Sci. USA 2001; 98:2703-2706

26. Holtwick R, van EM, Skryabin BV, Baba HA, Bubikat A, Begrow F, Schneider MD, Garbers DL, Kuhn M. Pressure-independent cardiac hypertrophy in mice with cardiomyocyte-restricted inactivation of the atrial natriuretic peptide receptor guanylyl cyclase-A. J Clin Invest. 2003; 111:1399-1407

27. Yang X.M., Philipp S, Downey J.M. Atrial natriuretic peptide administered just prior to reperfusion limits infarction in rabbit hearts. Basic Res Cardiol. 2006; 101:311-318

28. Braunewell K.H., Brackmann M, Schaupp M., Spilker C, Anand R., Gundelfinger E.D. Intracellular neuronal calcium sensort (NCS) protein VILIP-1 modulates cGMP signalling pathways in transfected neural cells and cerebellar granule neurons. J Neurochem. 2001; 78:1277-1286 
29. Rosenkranz AC, Woods RL, Dusting GJ, Ritchie RH. Antihypertrophic actions of the natriuretic peptides in adult rat cardiomyocytes: importance of cyclic GMP. Cardiovasc Res. 2003; 57:515522

30. Oliver PM, Fox JE, Kim R, Rockman HA, Kim HS, Reddick RL, Pandey KN, Milgram SL, Smithies O, Maeda N. Hypertension, cardiac hypertrophy, and sudden death in mice lacking natriuretic peptide receptor A. Proc Natl Acad Sci. USA 1997; 94:14730-14735

31. Dickey DM, Flora D.R., Bryan PM, Xu X., Chen Y., Potter LR. Differential regulation of membrane guanylyl cyclases in congestive heart failure: natriuretic peptide receptor (NPR-B)-B, Not NPR-A, is the predominant natriuretic peptide receptor in the failing heart. Endocrinology 2007; 148:3518-3522

32. Soeki T, Kishimoto I, Okumura H, Tokudome T, Horio T, Mori K, Kangawa K. C-type natriuretic peptide, a novel antifibrotic and antihypertrophic agent, prevents cardiac remodeling after myocardial infarction. J Am Coll Cardiol. 2005; 45:608-616

33. Cody RJ, Atlas SA, Laragh JH, Kubo SH, Covit AB, Ryman KS, Shaknovich A, Pondolfino K, Clark M, Camargo MJ, Scarborough RM, Lewicki JA. Atrial natriuretic factor in normal subjects and heart failure patients. Plasma levels and renal, hormonal and hemodynamic responses to peptide infusion. J Clin Invest. 1996; 78:1362-1374

34. Tsutamoto T, Kanamori T, Morigami N, Sugimoto Y, Yamaoka O, Kinoshita M. Possibility of downregulation of natriuretic peptide receptor coupled to guanylyl cyclase in peripheral vascular beds of patients with chronic severe heart failure. Circulation 1993; 87:70-75

35. Bryan PM, Xu X., Dickey DM, Chen Y, Potter LR. Renal hyporesponsiveness to atrial natriuretic peptide in congestive heart failure results from reduced atrial natriuretic peptide receptor concentrations. Am J Physiol Renal Physiol. 2007; 292:F1636-F1644

36. Kim SZ, Cho KW, Kim SH. Modulation of endocardial natriuretic peptide receptors in right ventricular hypertrophy. Am J Physiol. 1999; 277:H2280-H2289

37. Del Ry S, Cabiaty M, Lionetti V, Emdin M, Recchia FA, Giannessi D. Expression of C-type natriuretic peptide and of its receptor NPR-B in normal and failing hearts. Peptides 2008; 29:2208-2215

38. Andreassi MG, Del Ry S, Palmieri C, Clerico A, Biagini A, Giannessi D. Up-regulation of "clearance" receptors in patients with chronic heart failure: a possible explanation for the resistance to biological effects of cardiac natriuretic hormones. Eur J Heart Failure 2001; 3:395397

39. Christoffersen TE, Aplin M, Strom CC, Sheikh SP, Skott O, Busk PK, Haunso S, Nielsen LB. Increased natriuretic peptide receptor $\mathrm{A}$ and $\mathrm{C}$ gene expression in rats with pressure-overload cardiac hypertrophy. Am J Physiol Heart Circ Physiol. 2006; 290:H1635-H1641

40. Potter LR, Garbers DL. Protein kinase C-dependent desensitization of the atrial natriuretic peptide receptor is mediated by dephosphorylation. J Biol Chem. 1994; 269:14636-14642

41. Potter LR. Phosphorylation-dependent regulation of the guanylyl cyclase-linked natriuretic peptide receptor B: dephosphorylation is a mechanism of desensitization. Biochemistry 1998; $37: 2422-2429$

42. Bryan PM, Potter LR. The atrial natriuretic peptide receptor (NPR-A/GC-A) is dephosphorylated by distinct microcystin-sensitive and magnesium-dependent protein phosphatases. J Biol Chem. 2002; 277:16041-16047 
43. Schlüter KD, Piper HM. Regulation of growth in the adult cardiomyocytes. FASEB J. 1999; $13: 17-22$

44. Tamura N, Garbers DL. Regulation of the guanylyl cyclase-B receptor by alternative splicing. J Biol Chem. 2003; 278:48880-48889 
Figure legends

Figure 1: Cardiac Expression of VILIP-1. A) Detection of VILIP-1 mRNA in rat tissues by RNAse Protection assay. GAPDH served as control. B) Confirmation of VILIP-1 protein expression by western blot in lysates from human and rat left ventricles and H9c2 cells. Immunocytological detection of VILIP-1 in neonatal (C), adult (D) rat cardiomyocytes, and H9c2 cells (E) (Scalebar: 100 $\mu \mathrm{m})$. Pictures were taken in red (Cy3-labeled secondary antibody).

Figure 2: Regulation of NPR-B signalling by VILIP-1 in H9c2 cells. A) Stable expression of VILIP-1 (inset) and enhancement of CNP-dependent cGMP-production. B) Increased binding of ${ }^{125} \mathrm{I}-$ CNP-22 in VILIP-1 overexpressing cells compared to mock. C) SiRNA-based knockdown of VILIP-1 was verified by western blot (inset) and led to decreased CNP-dependent cGMP production. D) Reduced binding of ${ }^{125} \mathrm{I}-\mathrm{CNP}-22$ in cells with reduced VILIP-1 protein level. All data are expressed as means \pm SEM ( $\mathrm{n}=4-5$ per group). ${ }^{* * *} \mathrm{p}<0.001,{ }^{* *} \mathrm{p}<0.01 ;{ }^{*} \mathrm{p}<0.05$ vs. mock or unrelated siRNA.

Figure 3: Antihypertrophic actions of CNP in H9c2 cells with VILIP-1 overexpression or knockdown. Cellular hypertrophy was induced by vasopressin (AVP). A) CNP displayed an increased potency to block protein synthesis in VILIP-1 transfected cells. B) VILIP-1 knockdown abolished the antihypertrophic property of CNP. All data are expressed as means \pm SEM ( $n=4$ per group). ${ }^{*} \mathrm{p}<0.05$ vs. Basal (non-stimulated cells); $\# \mathrm{p}<0.05$ vs. AVP alone; $\$ \mathrm{p}<0.05$ vs. mock or unrelated siRNA in cells treated with AVP+CNP

Figure 4: Guanylyl cyclase assay of failing rat hearts. Cardiac membranes were assayed for guanylyl cyclase activities in the presence or absence of various activators. Maximal hormonedependent ( $1 \mu \mathrm{M}$ CNP) activity was reduced in membranes from rats with MI compared with shamoperated animals. Triton-X100/ $\mathrm{Mn}^{2+}$-dependent guanylyl cyclase activity was comparable between both groups. All data are expressed as means \pm SEM ( $\mathrm{n}=4-5$ per group). ${ }^{* * *} \mathrm{p}<0.001 ;{ }^{*} \mathrm{p}<0.05$ vs. Basal; $\# \mathrm{p}<0.05$ vs. Sham; n.s. = not significant.

Figure 5: VILIP-1 protein expression in failing rat hearts. A) Detection of VILIP-1 protein expression in the left ventricle of ventricles of rats with MI or controls (sham) by Western blot. GAPDH protein expression served as control. B) Normalization of VILIP-1 expression to GAPDH expression (A.U. $=$ arbitrary unit). Data are expressed as means \pm SEM ( $n=4$ per group) ${ }^{*} \mathrm{p}<0.05$ vs. Sham.

Table 1: Heart failure parameters. Values are expressed as the means \pm SEM. HW, heart weight; BW, body weight; LV, left ventricle; LVEDD, LV end-diastolic diameter; LVESD, LV end-systolic diameter; PWT, LV posterior wall thickness; LV FS, LV fractional shortening; LV EF, LV ejection fraction; dP/dtmax, LV contractility; dP/dtmin LV relaxation; LVEDP, LV end-diastolic pressure; BNP, brain natriuretic peptide. 
Fig 1:

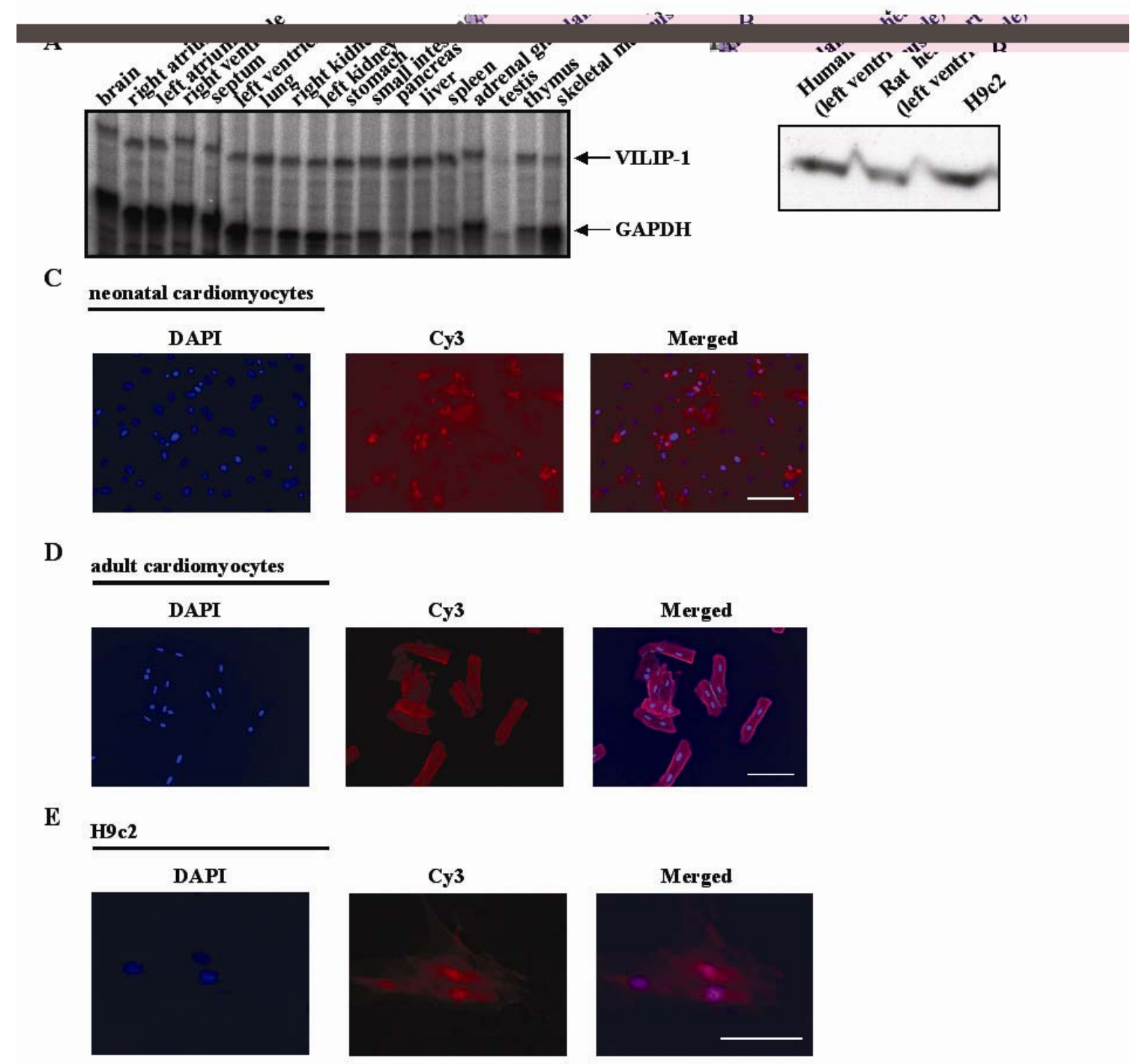


Fig 2:
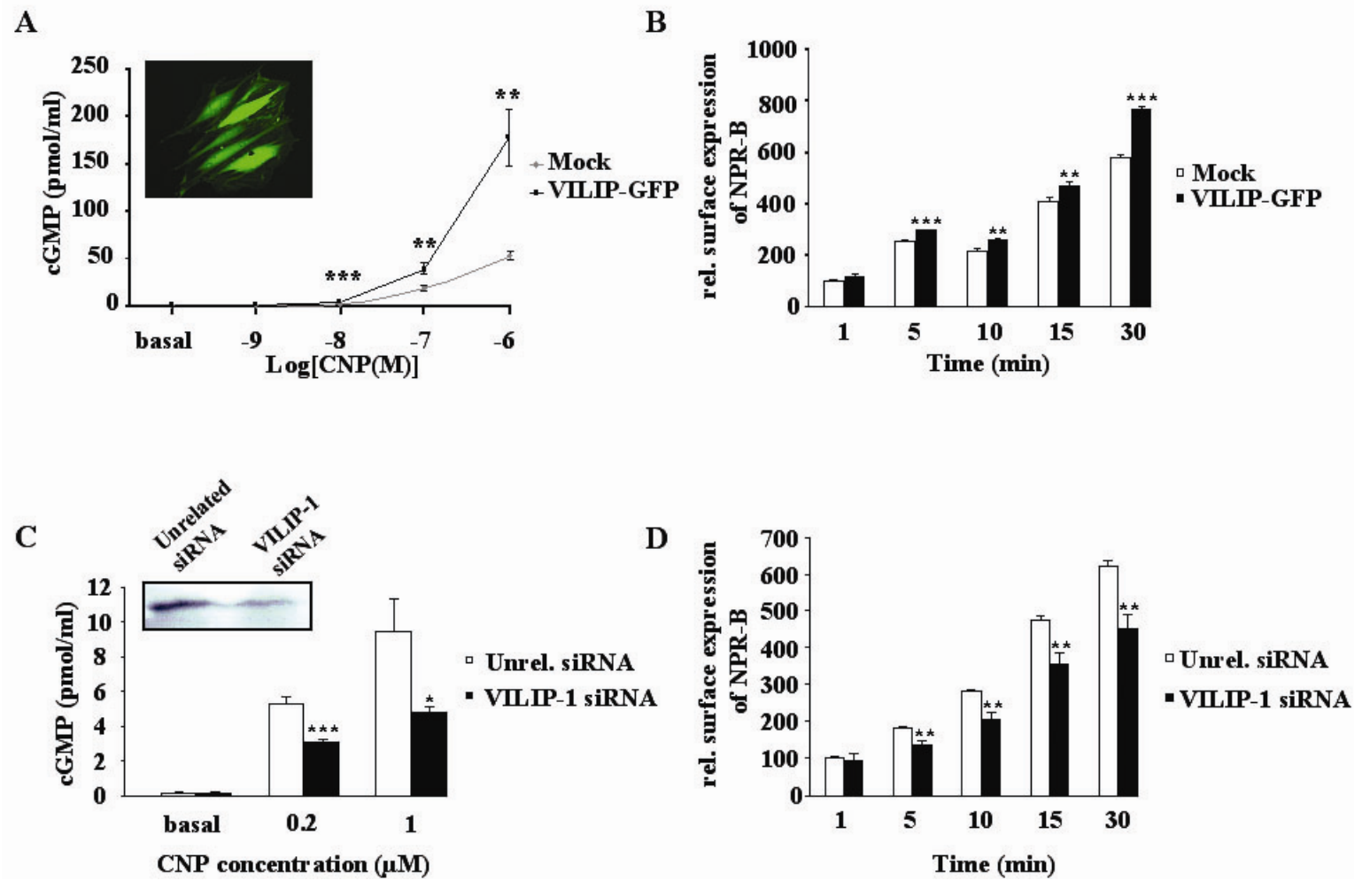
Fig 3:

A
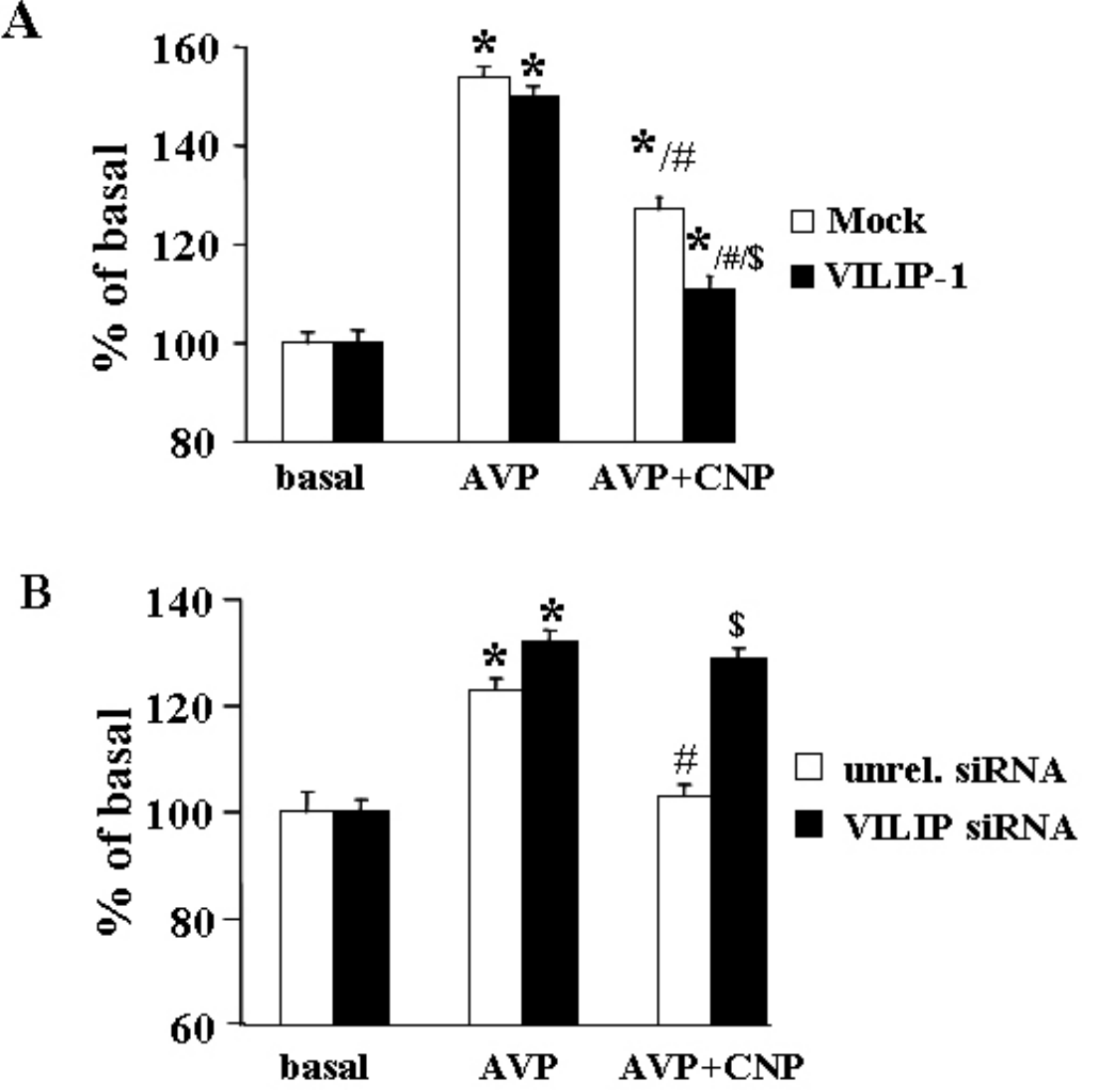
Fig. 4:

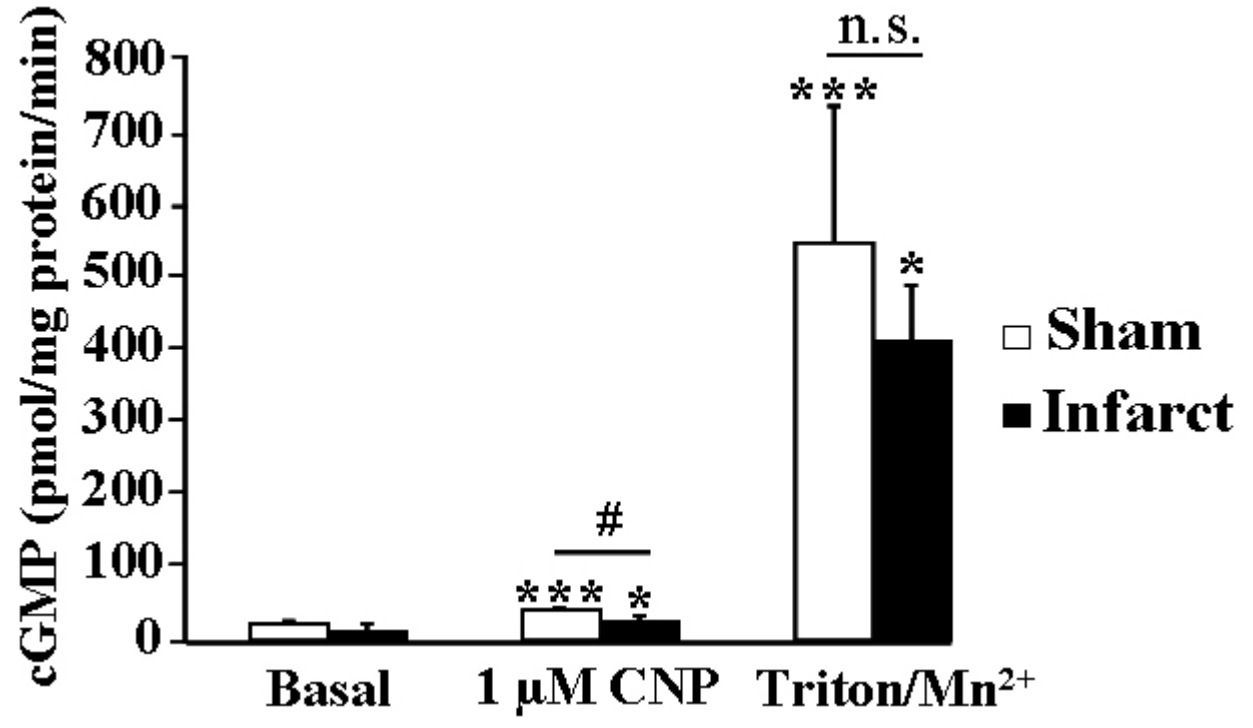


Fig. 5:

A

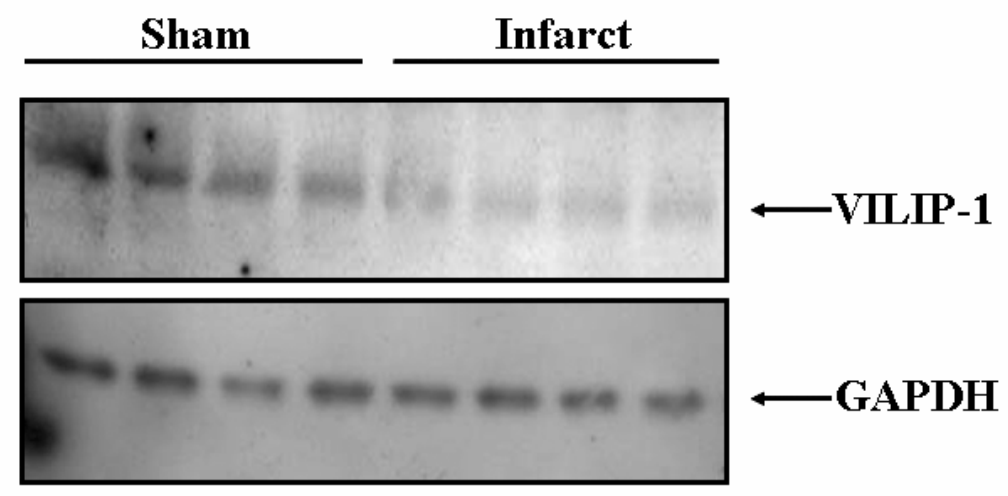

B

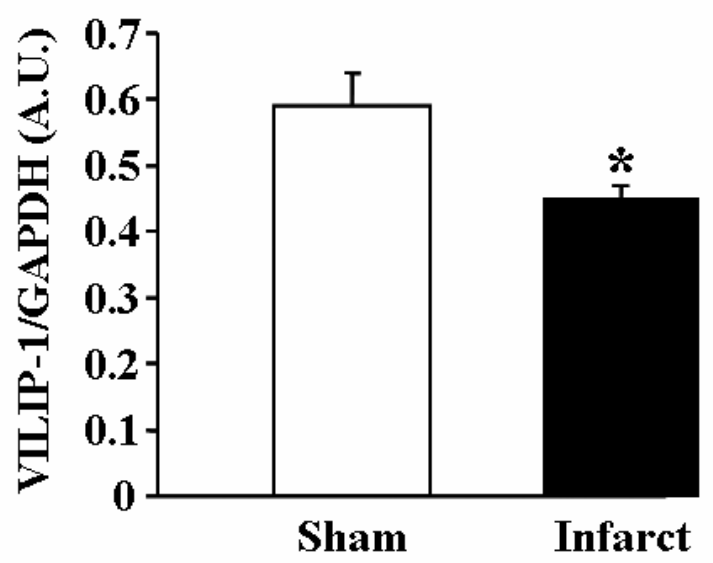


Table 1:

Table 1. Heart failure parameters

\begin{tabular}{|c|c|c|c|c|c|c|c|}
\hline \multirow[b]{2}{*}{ Body weight (g) } & \multicolumn{3}{|c|}{ Sham } & \multicolumn{2}{|c|}{ Infarct } & \multicolumn{2}{|c|}{$P$ value } \\
\hline & 396 & \pm & 12 & 364 & \pm 14 & & 0.13 \\
\hline Heart weight (mg) & 1309 & \pm & 46 & 1458 & \pm 37 & & 0.03 \\
\hline HW/BW (mg/g) & 3.3 & \pm & 0.1 & 4.1 & \pm 0.2 & & 0.02 \\
\hline LV weight (mg) & 473 & \pm & 13 & 609 & \pm 17 & $<$ & 0.001 \\
\hline LV/BW (mg/g) & 1.3 & \pm & 0.04 & 1.54 & \pm 0.02 & $<$ & 0.001 \\
\hline LVEDD (mm) & 8.3 & \pm & 0.02 & 11.1 & \pm 0.2 & $<$ & 0.001 \\
\hline LVESD (mm) & 4.4 & \pm & 0.02 & 9.7 & \pm 0.2 & $<$ & 0.001 \\
\hline PWTILVEDD & 0.16 & \pm & 0.01 & 0.13 & \pm 0.01 & & 0.01 \\
\hline LVFS $\%$ & 47 & \pm & 1 & 12 & \pm 2 & $<$ & 0.001 \\
\hline LVEF (\%) & 83 & \pm & 1 & 29 & \pm 1 & $<$ & 0.001 \\
\hline $\mathrm{dP} / \mathrm{dtmax}(\mathrm{mmHg} / \mathrm{s})$ & 3369 & \pm & 170 & 2908 & \pm 191 & & 0.01 \\
\hline $\mathrm{dP} / \mathrm{dtmin}(\mathrm{mmHg} / \mathrm{s})$ & 4185 & \pm & 195 & 2489 & \pm 162 & $<$ & 0.001 \\
\hline LVEDP (mmHg) & 7.9 & \pm & 1 & 14 & \pm 1.5 & & 0.003 \\
\hline Plasma BNP (fmoliml) & 8.5 & \pm & 0.8 & 18.7 & \pm 2.5 & & 0.002 \\
\hline
\end{tabular}

